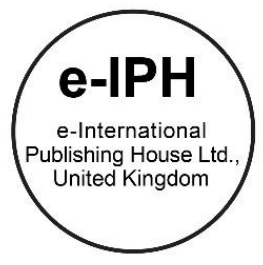

\title{
The Psychological Ownership of Ethnobotanicals through Education
}

\author{
Sofia M. Penabaz-Wiley¹, Mitsunari Terada1', Isami Kinoshita² \\ ${ }^{1}$ Chiba University Graduate School of Horticulture, 648 Matsudo, Matsudo City 271-8510, Japan \\ ${ }^{2}$ Chiba University Faculty of Horticulture, 648 Matsudo, Matsudo City 271-8510, Japan \\ sofiapenabaz@gmail.com, play@chiba-u.jp, isamikinoshita@faculty.chiba-u.jp \\ Tel : +81-90-1973-6765
}

\begin{abstract}
Ethnobotanical knowledge is being forgotten in the modern world. A qualitative research case study was conducted over two summers with caretakers and children to study how ethnobotanical content-based environmental education (EE) in English classes can impact psychological ownership (PO) of plants. The objective was to study what increases PO of ETBs. Purposive sampling, notes, observation, and recording were used. The second summer, a questionnaire was employed. Results showed that caretakers hinder children's enthusiasm about disliked plants. However, they also change their perspectives with EE. PO increased beginning with teacher-centered lessons; identity and behavior arose from creative kinesthetic-tactile learning and ingestion.
\end{abstract}

Keywords: ethnobotany; psychological ownership; education; Houttuynia cordata

eISSN: 2398-4287 @ 2018. The Authors. Published for AMER ABRA cE-Bs by e-International Publishing House, Ltd., UK. This is an open access article under the CC BYNC-ND license (http://creativecommons.org/licenses/by-nc-nd/4.0/). Peer-review under responsibility of AMER (Association of Malaysian Environment-Behaviour Researchers), ABRA (Association of Behavioural Researchers on Asians) and cE-Bs (Centre for EnvironmentBehaviour Studies), Faculty of Architecture, Planning \& Surveying, Universiti Teknologi MARA, Malaysia.

DOI: https://doi.org/10.21834/e-bpj.v3i8.1415

\subsection{Introduction}

With lowering birthrates, an aging population, long working hours, and increasing incidence of the nuclear family lifestyle, opportunities for communication with the next generation have gone down not only in Japan, but worldwide (Momir et al., 2015; Sharif et al., 2015). In addition, for purposes of resilience and sustainability people should be connected with nature, however, with little reason to do so in the modern age children have scant traditional knowledge (TK) of nature and its specific areas of usefulness (Kinoshita, 1992). Ethnobotany (ETB) is the traditional use of plants by peoples in the cultural context or in plant-human relations, for example, as food or medicine, and TK is the knowledge needed to know how to use those plants (Soejarto et al., 2005) In order to foster a deeper connection with nature, environmental education (EE) can be used to increase interest in it (Soykan \& Atasoy, 2012; Valderrama-Hernández et al., 2017). This study hypothesizes that EE can be used for retention of TK as well. However, close adults have a deep impact on children's beliefs (Meiboudi et al., 2011). Since modern adults may have little interest or even dislike natural elements, this is passed on to their children. Thus, the problem is that the TK of ETB plants is being devastated due to the modern lifestyle, and also because of a failure to transmit TK to the next generation the fading of cultural knowledge has coupled with decreased possibilities for resilience and sustainability in the face disaster.

\subsection{Research Background}

\subsubsection{Ethnobotany}

eISSN: 2398-42870 2018. The Authors. Published for AMER ABRA cE-Bsby e-International Publishing House, Ltd., UK. This is an open access article under the CC BYNC-ND license (http://creativecommons.org/licenses/by-nc-nd/4.0/). Peer-review under responsibility of AMER (Association of Malaysian Environment-Behaviour Researchers), ABRA (Association of Behavioural Researchers on Asians) and cE-Bs (Centre for Environment-Behaviour Studies), Faculty of Architecture, Planning \& Surveying, Universiti Teknologi MARA, Malaysia.

DOI: https://doi.org/10.21834/e-bpj.v3i8.1389 
This study uses the ETB plant Houttuynia cordata, commonly known as Dokudami, as a focus plant because, although it is disliked in modern Japan for its strong smell as a garden weed (Murakami, 2011), it is a deeply useful and important part of Japanese traditional culture (Yuri, 2010). Also known as Jyuyaku, or 'Ten Medicines' in Japanese pharmacopoeia, it has many applications, such as: lowering blood pressure, inflammation, bowel problems, antibacterial, and for the purpose of this study, lowering fever and body temperature (Shogakukan, 1985) in a cooling summer tea. In other cultures, it is eaten as a medicinal edible ETB (Penabaz-Wiley, 2017; Yang \& Jiang, 2009). However, despite common availability in Japan, it's TK is being forgotten, and has gained the reputation of a commonly disliked, strongly scented weed. Thus, this research hypothesizes that psychological changes in attitude towards $\mathrm{H}$. cordata could be used to establish new methods for reversing perceptions towards ETB plants in more positive directions, resulting in human and environmental sustainability.

Another traditional ETB was also selected; Morus bombycis. M. bombycis is also known as Japanese mulberry, and Kuwa or Yamaguwa in Japanese. It was selected due to its historical fame as a fruit-bearer, as silkworm food, and as a medicinal tea and a plant with edible spring shoots (Shogakukan, 1985) and being found in similar locations, is weedy. However, from a preliminary study by the first author, having an innocuous scent it produces little reaction as compared to $\mathrm{H}$. cordata by participants. This is supported by previous research stating that scent has effect on emotion (Mustafa et al., 2017). Thus, the main cultural difference being scent, M. bombycis was chosen as a comparative to study alongside $\mathrm{H}$. cordata.

\title{
1.1.2 Psychological Ownership
}

Psychological ownership (PO) is the perceived, not necessarily legally true, ownership of an object, and can increase based on three factors: time invested, power in decision-making, and intimate knowledge about it (Pierce et al., 2003). It increases the order of interest to identity to behavior. The use of unusual materials of culture (Guerra \& Zuccoli, 2014) involved in TK, namely ETB plants that could be used in art and food were included as part of the lesson to increase PO considering how strongly people feel towards these aspects of their cultures (Sharif et al., 2016).

\subsubsection{Environmental Education}

EE about the ETB plants in this study was designed to instill creativity (Davies et al., 2013; Pecheanu \& Tudorie, 2015; Saliceti, 2015). It was done in a Content and Language Integrated Learning (CLIL) English classroom. Marketing EE to a group interested in English study could be seen as a limitation to the study of the natural environment. However, it is realistic for content-based language learning, as well as real modern life. It is commonly thought that learning English is necessary. Enthusiasm in it can increase by incorporating other focus subjects, thus maximizing participation by widening scope (Caciuc, 2014). Interest in learning English is high, and because content-based and interdisciplinary studies are engaging to the students, this particular study was considered relevant to use in environmental education. In addition, the ETB realia employed in this study was thought to be possibly beneficial for TK retention and cultural evolution. The use of creative craft activities and kinesthetic learning in the humanistic environment was utilized for deep impact on participants (Elena, 2015; Petrenko, 2017; Zivitere et al., 2015) and to find what is effective for the PO of ETBs.

\subsection{Aim and Objective}

This research aimed to study how change in adults' and children's perceptions through environmental education (EE) might affect PO of ETB plants. The specific objective of this paper was to reveal what, if anything, increases PO of ETB plants and specifically to what extent according to the three laws of PO. The plant $\mathrm{H}$. cordata was used as a focal ETB due to its traditional importance, diametrically opposed to its currently negative perception status. While there is research about food uses of plants for transmitting TK (Sharif et al., 2016), and there are studies in art for EE (Wiegerová \& Navrátilová, 2017), there were no studies found incorporating both EE using consumption and art for changing negative feelings regarding plants to identifying with them as cultural necessities. Moreover, no ETB studies have been found incorporating the idea of PO. The current research lacks this particular interdisciplinary aspect. This study was built incorporating several referenced researches in order to answer the aim.

\author{
Nomenclature \\ PO Psychological Ownership \\ ETB Ethnobotany \\ EE Environmental Education \\ H. cordata Houttuynia cordata / Dokudami in common Japanese / Juuyaku in Japanese Pharmacopoeia / Chameleon Plant \\ M. bombycis Morus bombycis / Kuwa or Yamaguwa in common Japanese / Mulberry
}

\subsection{Methods}

This was a qualitative action research case study within the participatory research approach (Dayaratne, 2016) done on children and their caretakers brought together into the EE classroom over two summers (Process 1 and Process II) in order to test the efficacy of ETB-based EE on changing perspectives for PO (See Tables 1 and 2). The methodology was designed using different kinds of classroom pedagogies (Caciuc, 2014; Davies, 2013; Elena, 2015; Guerra, 2014; Higashimura, 2012; Petrenko, 2017; Saliceti, 2015; Valderrama-Hernandez et. al., 2017; Zivitere et al., 2015) to study changes in participant's attitudes towards $H$. cordata and $M$. bombycis, as delineated in Table 1. Sample selection was done through purposeful selection with a citywide advertisement (Palinkas et al., 2015). Children and parents with preschool children interested in classes about nature and English were targeted. An oral informed 
consent was obtained from the parents and caretakers for participation in the study. The research examined reactions of subjects to an ETB plant not in just one aspect, but in three modes of education (Elena, 2015): traditional teacher-centered learning, crafts using ETB plants for hands-on student-centered learning (Wan Yunus \& Mat Ali, 2018), and finally ingestion of the focus ETB plant (Md. Sharif et

Table 1 The action research process flow and associated EE type

\begin{tabular}{l}
\hline Process I 1st ETB EE Lesson Flow (Summer 2015) \\
\hline 1 Asked: "If you like Dokudami, raise your hand." (Introductory inquiry) \\
2 Lecture: crafts and nature with children. (Lecture-style EE) \\
3 Leaf rubbing art with $H$. cordata and other leaves. (Craft, Kinesthetic tactile) \\
4 ETB lecture on $H$. cordata and M. bombycis: ecology, food, medicine, and global practices. (Lecture EE, TK) \\
5 Changes in perspectives. (Written responses)
\end{tabular}

Process I $2^{\text {nd }}$ ETB EE Lesson Flow (Summer 2016)

Participants: Children ages 3 6 ( $\mathrm{N}=19), 7 \sim 10(\mathrm{~N}=33)$; Caretakers, 20 39 $(\mathrm{N}=9), 40 \sim 70(\mathrm{~N}=7)$

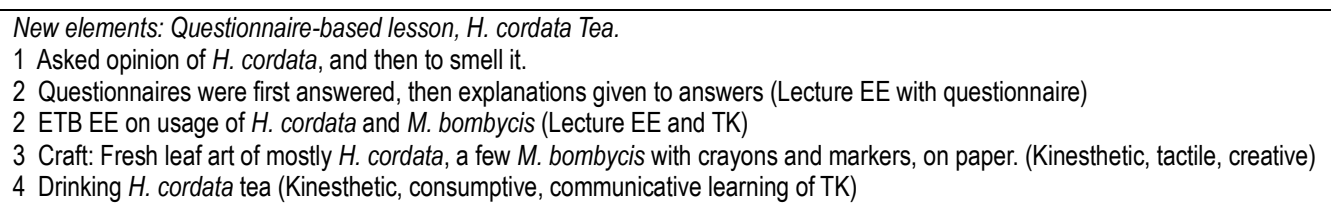

al., 2018), in order to see which might have deeper effects. The lesson structure followed the characteristics of intercultural humanitarian education (Petrenko, 2017) having pedagogical creativity (Zivitere et al., 2015).

Limitations to the methods were that this was a one-time per year study, and that not all children could drink the tea. As shown in Table 1, Process I in the first summer, 2015 consisted of various methods of EE, resulting in a kinesthetically art-based as well as traditional lecture style workshop.

Table 2 Participants, Data recovered, and Research Dates. [Of returned questionnaires, only some $(17 / 29,17 / 21)$ were valid.]

\begin{tabular}{llllllll}
\hline Year & Process & Ages 3-6 & Ages 7-10 & Adults (Fem) & Drank Tea & Questionnaire & Valid / Returned questionnaires \\
\hline 2015 & I & 14 & 0 & 12 & No & No & N/A \\
2016 & II Morning & 2 & 29 & 0 & No & Yes & $17 / 29$ \\
2016 & II Afternoon & 17 & 4 & 16 & Yes & Yes & $17 / 21$ \\
\hline
\end{tabular}

It was designed for all ages. At the end of the lesson, a question was posed to the caretakers to see what effect EE had had on the deeply-rooted dislike of $H$. cordata, as well as asking if they enjoyed the lesson. The question was "Rate your interest change in $H$. cordata, 1 being not at all, 2, so-so, 3, yes, 4 very, and 5, incredibly interested. Based on this, observations and recordings the class gave valuable insights seen in the results (See Table 3 ).

In the second summer of 2016, Process II, as it was action research, improving the research method was attempted with a questionnaire, two lessons instead of just one, and drinking $H$. cordata tea. The one in the morning involved only children ages 8 and above, and the one in the afternoon, wherein caretakers could bring smaller children. In afternoon classes, adults could fill in the questionnaire with preschoolers (ages 3-6). All classes followed identical lesson plans, thus results of both morning and afternoon classes were combined. The questionnaire integration into the lesson plan was done as though it were a normal classroom handout that would be handed back in to the teacher. The action of getting answers without influencing the subjects was by asking the questions, answers being written, and then subsequent discussion in communicative language-learning style. Questions were about previous knowledge and uses of $H$. cordata and $M$. bombycis, as well as perspectives on nature. The questionnaire followed the previous summer's flow in conjunction with a very similar, teacher-centered slide presentation. The classes also involved EE about husbandry of native animals with food, water and native plants. Then, collage art for tactile kinesthetic learning using fresh leaves of almost all $H$. cordata with only one $M$. bombycis leaf was done, though some participants requested more of the latter. After the craft, the class was over, and they gathered to drink $H$. cordata tea.

The classes and participants' reactions were recorded on audio, video and field notes and one question was answered for Process I, while for Process II the questionnaire handout was the main source of data, field notes were taken and the observations of classroom aides were inquired upon and recorded. Questionnaire results were Process II results were entered into SPSS and then further studied in Microsoft Excel. Word mining was done on the questionnaire using KH Coder to obtain results about what participants had enjoyed the most during the lesson.

\subsection{Results and Discussion}

This research aimed to study how EE might affect PO of ETB plants, as diagrammed in Figure 1. The objective was to study children and their caretakers in different classroom scenarios and find what effects PO, to what extent, and with what laws of PO. The methodological process, participant reactions, and findings for the study of the lesson processes I (1-5) and II (1-5) are shown in Table 3 and a further analysis of these results is provided in this section. 


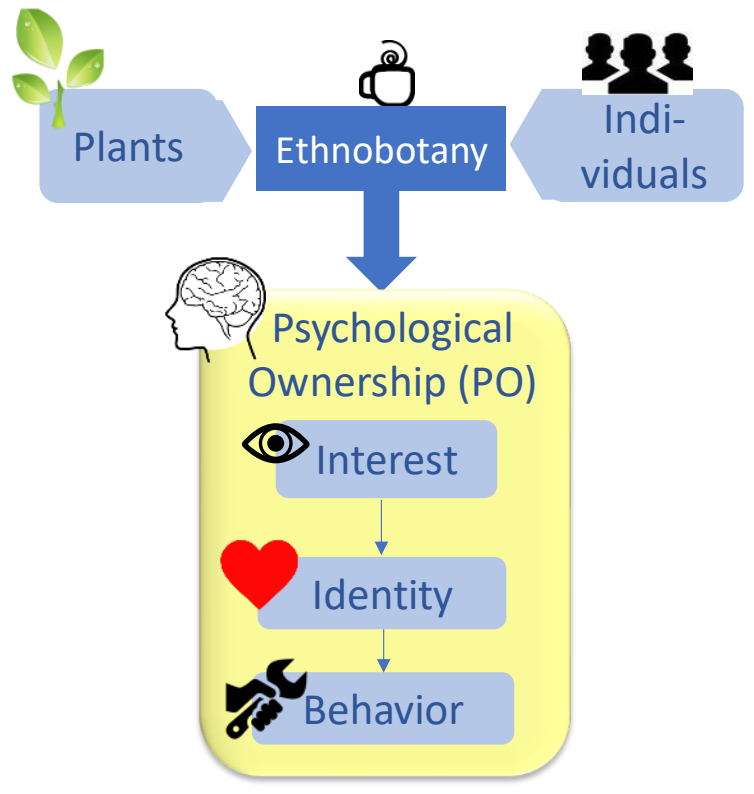

Figure-1 The relationship of psychological ownership with ethnobotany

\subsection{Findings of Process I.1-5: TK \& Crafts Lead to Psychological Ownership}

\subsubsection{Caretakers influence children's perceptions of ETBs (I.1-5)}

The first summer (Processes I.1, See Table 3), caretakers demonstrated their desire to influence children with their perspectives regarding Dokudami. The first main finding at this time were when the children raised their hands to answer that they liked the plant (Process I.1), the adults attempted to tell the children that Dokudami is not something you should like by scolding them, trying to lower their hands, or other behavior associating a negative feeling, an immediate indication of how deeply the caretakers believed it was wrong to like $\mathrm{H}$. cordata. Also that at this age, the children did not yet know this fact. Through personal observation (data not shown), it has been observed that children over the age of 8 tend to increasingly dislike $H$. cordata. At this starting point, it was clear that there was no PO on the part of the caretakers, and that if any time had been spent with the plant, it was trying to rid their yard of the noxious weed. This was considered good for the study, as it was beginning with a blank slate of PO, or even one in the negative that could possibly evolve with three factors: time invested, power in decision-making, and intimate knowledge (Pierce et al., 2013).

\subsubsection{Plant dislike was weaker than urge to play. Teachers can create the right atmosphere for ETB interest. (I.3 \& I.4)}

Over the course of the lesson, less negative behavior regarding $H$. cordata was observed. The recordings showed caretakers' increased curiosity to learn more, about ETB plants and about the ways that nature could be used to interact with the children. The EE teacher's actions and reactions influenced caretakers and children in creating a positive ETB atmosphere. The aspects of time invested and intimate knowledge were being employed and resulting in observable interest among respondents.

\subsubsection{Crafts coupled with TK and Global TK created new interest in $H$. cordata. (I.5)}

Requests for cooking methods of $H$. cordata and $M$. bombycis were also requested. Considering the drastic change, this was a surprising result. At the end of the class, all caretakers said they had enjoyed the lesson. The PO laws of time invested and intimate knowledge continued to be employed. With caretaker-child teams doing crafts, power in decision-making was given to participants. This gave way to deepened interest and created some identity with the plant, perhaps understanding it as part of their culture.

\subsubsection{EE coupled with crafts affects psychological ownership (I.1-5)}

In the end, out of 12 caretakers on a Likert Scale of 1-4, with 4 being very interested, two wrote they were very interested in $H$. cordata and two wrote they were interested in the plant. Moreover, all participants had shown interest, and the class was so popular that for the subsequent summer, the lesson number was doubled. Thus $1 / 3$ of adult participants changed perspectives more than the others; this was deduced to be identity to some degree. In the ETB-based EE, children demonstrated even more positivity and interest than in the beginning, and only one demonstrated aversion of it in crafts. Though a small and simple set of results was obtained, (See Tables 2 and 3), it gave sufficient information for moving forward with the action research. Incorporation of $H$. cordata tea and a questionnaire were decided upon for Process II in order to further clarify the results and see what, if anything, would move participants to the extent of Behavior in PO of ETBs. 
Table 3 Action research process, interventions, participant reactions and findings. Main findings and titles in bold font.

\begin{tabular}{|c|c|c|c|}
\hline $\begin{array}{l}\text { Pro- } \\
\text { cess }\end{array}$ & \begin{tabular}{|l} 
PROCESS \& \\
INTERVENTION
\end{tabular} & PARTICIPANTS \& REACTIONS & FINDINGS \\
\hline \multirow[t]{2}{*}{ I.1-5 } & \multirow{2}{*}{$\begin{array}{l}\text { 1st ETB EE Lesson } \\
\text { Flow; One Class, } \\
\text { Summer 2015 } \\
\end{array}$} & CHILDREN CARETAKERS & \multirow[t]{2}{*}{$\begin{array}{l}\text { Cumulative findings of Process I: ETB-Based EE with crafts and TK } \\
\text { increases psychological ownership of ETB plants to identity level. }\end{array}$} \\
\hline & & Ages: $3 \sim 6(14)$ & \\
\hline \multirow[t]{3}{*}{1} & \multirow[t]{3}{*}{$\begin{array}{l}\text { Asked: "If you like } \\
\text { Dokudami, raise your } \\
\text { hand." }\end{array}$} & $\begin{array}{l}\text { Children: } 12 / 14 \text { raised their hands, many } \\
\text { smiling. }\end{array}$ & Children did not know about $H$. cordata and were just excited. \\
\hline & & \multirow[t]{2}{*}{$\begin{array}{l}\text { Adults: None raised hands. Instead, 10/12 } \\
\text { caretakers chastised the children. }\end{array}$} & $\begin{array}{l}\text { Caretakers tried to teach their negative perceptions of } H \text {. cordata to } \\
\text { children. }\end{array}$ \\
\hline & & & $\begin{array}{l}\text { Caretakers reactions include attempts to influence children's } \\
\text { perceptions of ETB plants. }\end{array}$ \\
\hline 2 & Lecture: crafts \& nature & Attentive & $\mathrm{n} / \mathrm{a}$ \\
\hline \multirow[t]{2}{*}{3} & \multirow[t]{2}{*}{$\begin{array}{l}\text { Leaf rubbing art with } H \text {. } \\
\text { cordata and other leaves. }\end{array}$} & $\begin{array}{l}\text { Only } 1 \text { child refused to use it; } 13 / 14 \text { did not } \\
\text { seem to mind. } 2 / 12 \text { caretakers did not use } H \text {. } \\
\text { cordata for art until prompted, then reluctantly } \\
\text { did. }\end{array}$ & $\begin{array}{l}\text { Two caretakers showed dislike of } H \text {. cordata by boycotting it at first. } \\
\text { However, other caretakers used it promptly, though they hadn't cared for } \\
\text { the plant before the lecture, they used it. }\end{array}$ \\
\hline & & $\begin{array}{l}\text { They all did crafts together, children were } \\
\text { smiling, offering ideas and materials for the } \\
\text { project, caretakers were teaching how to do } \\
\text { the activity. }\end{array}$ & $\begin{array}{l}\text { For most, plant dislike was weaker than desire to play. Thus, if } \\
\text { teachers make a fun controlled space (action and time), negative } \\
\text { perceptions can change into interest. }\end{array}$ \\
\hline 4 & $\begin{array}{l}\text { Lecture on both ETBs' } \\
\text { ecology, food, medicine, } \\
\text { global TK. }\end{array}$ & $\begin{array}{l}\text { Caretakers asked questions like how to cook } \\
\text { H. cordata. Expressions showed surprise and } \\
\text { interest during the lecture. }\end{array}$ & $\begin{array}{l}\text { EE seemed valuable due to TK and psychological identity gained with the } \\
\text { plants. }\end{array}$ \\
\hline \multirow[t]{3}{*}{5} & \multirow[t]{3}{*}{$\begin{array}{l}\text { Writing of changes in } \\
\text { perspectives. After-class } \\
\text { conversations. }\end{array}$} & $\begin{array}{l}\text { Children came to say they liked the class, they } \\
\text { wanted to play in nature with their caretakers, } \\
\text { they wanted to play with } H \text {. cordata again. }\end{array}$ & \multirow[t]{3}{*}{$\begin{array}{l}\text { Crafts coupled with TK and global TK fostered new interest in } \mathrm{H} \text {. } \\
\text { cordata. }\end{array}$} \\
\hline & & $\begin{array}{l}\text { Caretakers wrote } 1-5 \text { level of interest change } \\
\text { on paper. }\end{array}$ & \\
\hline & & $\begin{array}{l}\text { 4/12, change: } 2 / 4=y e s, \text { now interested and } \\
2 / 4=\text { very interested }\end{array}$ & \\
\hline \multicolumn{4}{|c|}{$\begin{array}{l}\text { Findings from Process I action research showed that EE coupled with crafts can influence PO. In order to establish a clearer relationship, in the next } \\
\text { summer, 2016, a questionnaire handout as well as the drinking of } H \text {. cordata tea was added to the lessons. }\end{array}$} \\
\hline \multirow[t]{3}{*}{ II.1-5 } & \multirow{3}{*}{$\begin{array}{l}\frac{\text { 2nd }^{\text {ETB EE Lesson }}}{\text { Flow; Two Classes, }} \\
\underline{\text { Summer } 2016}\end{array}$} & CHILDREN CARETAKERS & \multirow{3}{*}{$\begin{array}{l}\text { Cumulative findings of Process / were that Age / TK / ETB / degree } \\
\text { of physiological integration and the } 3 \text { laws of PO can change PO of } \\
\text { ETBs in the EE classroom. }\end{array}$} \\
\hline & & Ages: 3 6(19) & \\
\hline & & $7 \sim 10(33)$ & \\
\hline 1 & $\begin{array}{l}\text { At first, they were asked } \\
\text { to say whether liked } H \text {. } \\
\text { cordata, then to smell. }\end{array}$ & $\begin{array}{l}\text { 2/26 children, aged 3 6 disliked it. They were } \\
\text { positive in the beginning, but then smelled it, } \\
\text { and stated they did not like it. (However, they } \\
\text { subsequently used it in crafts.) }\end{array}$ & $\begin{array}{l}\text { Even though disliked, crafts in both summers were able to draw } \\
\text { participants into the use of the plant. }\end{array}$ \\
\hline 2 & $\begin{array}{l}\text { Questionnaire questions } \\
\text { first, then explanations }\end{array}$ & $\begin{array}{l}\text { Caretakers filled in questionnaires and for } 3 \sim 6 \text {. } \\
7 \sim 9 \text { filled in their own. Some caretakers tried to } \\
\text { fill-in without asking } 3 \sim 6 \text { children their opinion. }\end{array}$ & $\begin{array}{l}\text { Caretakers tried to share their own perceptions as their children's' instead } \\
\text { of asking directly. Caretakers, again, trying to influence children's } \\
\text { responses. }\end{array}$ \\
\hline
\end{tabular}




\begin{tabular}{|c|c|c|c|}
\hline & & $\begin{array}{l}\text { (Limitation) Some, ages } 3 \sim 6 \text { insisted on doing } \\
\text { questionnaire answers alone. }\end{array}$ & $\begin{array}{l}\text { Children want to take action and desire autonomy. (Limitation finding) } \\
\text { It was hoped that adults would help children, but children wanted to write. } \\
\text { Admirable for them, but the results could not be read. Those } \\
\text { questionnaires were not included in the results. Does show intuitive } \\
\text { need for PO's decision-making aspect in personal growth. }\end{array}$ \\
\hline \multirow[t]{3}{*}{3} & \multirow[t]{3}{*}{$\begin{array}{l}\text { ETB EE on usage of } H \text {. } \\
\text { cordata and M. bombycis }\end{array}$} & Participants surprised by many uses. & \multirow{3}{*}{$\begin{array}{l}\text { Adults and children have their own interests, thus their questions } \\
\text { during the lecture reflect their interest in particular areas of what is } \\
\text { taught. }\end{array}$} \\
\hline & & $\begin{array}{l}\text { Children inquired on how to use plants for park } \\
\text { play. Adults asked recipes. }\end{array}$ & \\
\hline & & Liked EE on nature husbandry. & \\
\hline \multirow[t]{2}{*}{4} & \multirow[t]{2}{*}{\begin{tabular}{|l|} 
Craft: Fresh leaf art of \\
mostly $H$. cordata, a few \\
M. bombycis with crayons \\
and markers on paper.
\end{tabular}} & $\begin{array}{l}\text { Caretakers and children both: stated } \\
\text { enjoyment in doing crafts, smiled and } \\
\text { concentrated. Some adults learned how to } \\
\text { share their skills with children. }\end{array}$ & $\begin{array}{l}\text { The act of doing crafts together teaches not only crafts, but also how to } \\
\text { share actively with children, fostering interactive skills between } \\
\text { caretakers and small children. }\end{array}$ \\
\hline & & $\begin{array}{l}\text { The participants were "amazed at the leaf art } \\
\text { activity", "want to do it again", "excited for } \\
\text { future play with Dokudami \& Kuwa", "want to } \\
\text { play in nature". }\end{array}$ & $\begin{array}{l}\text { By using a culturally rich and important edible medicinal plants in a } \\
\text { hands-on workshop coupled with EE, people of different ages gained } \\
\text { interest and further, identity with them. }\end{array}$ \\
\hline \multirow[t]{6}{*}{5} & \multirow[t]{6}{*}{$\begin{array}{l}\text { Drinking } H \text {. cordata Tea } \\
\text { after class, and the } \\
\text { reactions to this }\end{array}$} & $\begin{array}{l}\text { (Limitation) Children ages } 7 \sim 10 \text { : some could } \\
\text { not obtain permission from parents. }\end{array}$ & $\begin{array}{l}\text { (Limitation finding) If children are used as subjects, it is best to get } \\
\text { permission earlier for ingestion. However, it was a one-time event and not } \\
\text { possible. }\end{array}$ \\
\hline & & $\begin{array}{l}\text { Everyone who drank expressed that they liked } \\
\text { it or did not express dislike except two (ages } \\
3-6 \text { ) stated dislike in II-2. } N=46 / 48 \text {. }\end{array}$ & $\begin{array}{l}\text { Increasing intensity of interest was observed with the verbal lesson, } \\
\text { then hands-on work, and finally ingestion of } H \text {. cordata as a tea. }\end{array}$ \\
\hline & & $\begin{array}{l}\text { Two mothers asked where they could buy } \\
\text { Dokudami tea (at the local drug store, sold as } \\
\text { Juuyaku). }\end{array}$ & $\begin{array}{l}\text { Clear desire to follow through was shown by interest in purchasing. } \\
\text { Possible difficulties in TK transmission socially could be due to } \\
\text { different nomenclature of plant and medicine. }\end{array}$ \\
\hline & & $\begin{array}{l}\text { Conversations about how to prepare tea from } \\
\text { tea bags, and how to collect fresh plants to } \\
\text { prepare the tea. }\end{array}$ & $\begin{array}{l}\text { Show PO by interest in continuing traditional cultural usage in } \\
\text { modern life. }\end{array}$ \\
\hline & & $\begin{array}{l}\text { Children came back several times for more } \\
\text { tea. Continuous positive comments in } \\
\text { conversation from adults. }\end{array}$ & $\begin{array}{l}\text { Children showed clear interest through actions. Caretakers showed } \\
\text { interest by asking how to use in the future. }\end{array}$ \\
\hline & & $\begin{array}{l}\text { The facility managers said later that they had } \\
\text { been worried that the children would dislike } \\
\text { the tea, but they stated surprise at how } \\
\text { popular it was. }\end{array}$ & $\begin{array}{l}\text { A creative, supportive and positive administration can enable good results } \\
\text { in EE classrooms. }\end{array}$ \\
\hline
\end{tabular}

\subsection{Findings of Process II: Various Influences on Perspective}

\subsubsection{New introductions and problems faced (ll.1-5)}

The second summer (Process II. Sections 1-5), new elements were the questionnaire style handout for more extensive input and $H$. cordata tea in order to observe the effects of bodily sensation on levels of PO of the ETB. The questionnaire incorporated into the lesson proved to be a useful but rather unwieldy tool in some cases. For simplification, if done again, the authors would only require writing for caretakers and children who wanted to fill in the sheet, and have another activity for smaller children to do. To get a more consistent result with younger children, only audio-visual, field notes, and art data for analysis would be taken.

\subsubsection{Though H. cordata was disliked, crafts drew participants into use. (II.1)}

It was clear that a few children (ages 3-6) who initially changed their perspectives of like to dislike because of the strong smell, did do the craft, precisely in the same way as in Higashimura's scent workshop in 2010 (Higashimura, 2012). Although there was a H. cordata coloring sheet prepared for anyone who might not want to use the leaves, everyone used $H$. cordata for art, and some children $3 \sim 6$ also used the coloring sheet in addition to the leaf craft. This again demonstrated the power of allowing decision-making through crafts, the 
desire to create in overcoming aversion to the plant, in turn creating an opportunity for time-spent and intimate knowledge about the ETB to osmotically flow into participants, resulting in mild (interest) to stronger (identity) PO.

\subsubsection{Caretakers influence children's responses (II.2) / Children desire autonomy (II.2) / Crafts together fosters interactive communication. (II.4)}

Consistent with their attitude the previous year, caretaker's again believed their opinions must be the same as their children's in Process II.2 (See Table 3). This indicates that in order to do a questionnaire for children with adults, the researcher must find a way to liberate the child from the caretaker's influence for those moments or to create a fair atmosphere for free expression. Moreover, children showed that they wanted autonomy and free expression (II.2), while being supported by their caretakers. Extensive research on PO has been done on Early Childhood Development, and this is a good example of the need of the child to create PO of different objects and actions in their world through decision-making power and individual time devoted to a task. It shows that this is a need in children that should be respected for emotional growth (Pierce et al., 2013). In this case, it also demonstrates the need for it with respect to creativity involving ETBs for establishing a connection leading to greater $\mathrm{PO}$.

In Figure 2, the larger drawing is an example of a child's leaf art. Note the use of English alongside the leaves. The drawing in the left-hand corner was drawn by a mother-daughter pair. Another related finding was that some caretakers do not know how to interact with their children (II.2), especially those still too young to draw. When the leaf collage craft involving gluing a leaf to paper and then making art with the result was done two caretakers who had not know how to share their creative abilities with their children both expressed pleasure at learning how to create artwork in a team (II.4). This is supported by research stating that learning culture from family and community is effective for transmitting TK (Md. Sharif et al., 2018). It was discovered that this also had a strong effect on PO of the ETBs; the act of doing work with loved-ones strengthens the feelings of identity and creates a desire to act (PO behavior) in favor of the object connecting people. Thus, resulting comments regarding a desire to do the crafts again and play together in the park, also demonstrating identity and future behavior involving ETBs were made by participants.

Table 4 Favorite aspects of Lesson Process II by text analysis of the questionnaire

\begin{tabular}{llllllll}
\hline Leaf/Craft & Dokudami & Nature & English & Other & Kuwa & Changed mind & All \\
14 & 10 & 4 & 4 & 4 & 3 & 2 & 2 \\
\hline
\end{tabular}

3.2.4 Adults' and children's interests. (II.3)

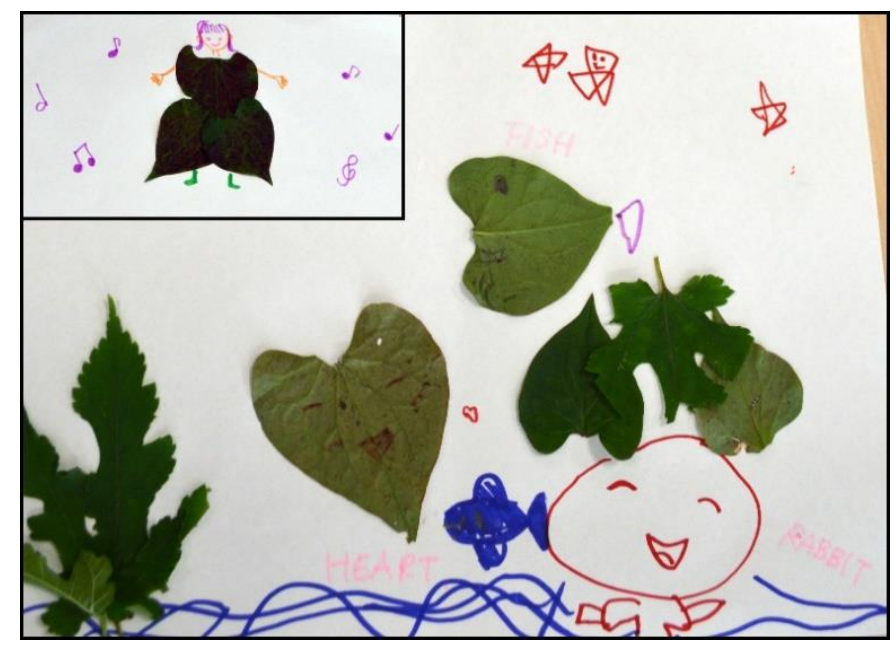

Figure 2 Example of crafts from the $2^{\text {nd }}$ Summer Class (Process II) with $H$. cordata and $M$. bombycis leaves

Caretakers and children were found to have interests based around age (II.3). Children showed clear interest through actions such as repeatedly drinking the tea. Caretakers showed interest by asking how to use in the future and where to buy the tea after the class (II.5). The elementary school children liked the crafts the best, whereas the caretakers vocally favored the tea better. However, everyone demonstrated an interest in $H$. cordata and some in M. bombycis as well through the lesson process for various reasons. In II.3, participants learned about husbandry and habitat value, as well as how to use ETB plants for interacting with nature, such as making a biotope or what animals can live off of the plants. Children asked questions about animals, and adults asked recipes and balcony pond methods. Adults said that they were happy to learn about nature husbandry, but expressed more interest and surprise in uses of ETB plants. They were affected by its cultural loss. It was noted that ETB uses in the EE classroom addressed physiological needs sensu (Maslow, 1943), the most basic need with tea, as well as higher needs of cultural knowledge, creativity, activity, and thought. Time 
dedicated and deepening knowledge of the subject created discussion leading to further questions, in each turn increasing PO of the ETBs for various participants, and leading from interest to identity, and for some, to future action plans.

\subsubsection{Clear desire for future use. (II.5)}

The questionnaire data and spoken and written results showed that, affected by the TK values imparted in the lesson (Antlová et al., 2015), the creative kinesthetic activities, and finally by the tea, participants had moved from interest to identity and some even to behavioral actions for the near future with regard to the plant. As for the tea-drinking, organizers from the university stated, "We were concerned that children would not like the H. cordata tea, however, they really liked it." Nine older children could not get permission, and two younger children did not want to drink the tea. Several children came back for seconds, but no adults did. People said in surprise, "it has a mild flavor", "it is good", "I am glad to learn about my culture", and three adults said they were going to buy some at the drug store. For the question of whether they liked the tea, except for two of the smaller children, 48 people stated they liked it, drank more, or stated nothing while drinking. This high number may have been due to mild flavor and hot weather that day, as $\mathrm{H}$. cordata cools the body.

According to the final resultant verbal comments after the tea-drinking, the participants were most interested in the ingestion of the tea, how it was made and how it felt, and observations by university organizers and the researcher led to this consensus.

The final written data collected before this in the questionnaire showed enthusiasm in learning the leaf craft, then drink tea, and following that, learn about $H$. cordata. Other elements of the lesson, such as biodiversity studies were also mentioned (See Table 4).

According to written comments after the lesson and before the tea-drinking, the caretakers were grateful to receive guidance regarding underutilized and underappreciated plants, as can be seen in these comments: "I will play in nature with my child. Also, the leaf art was fun," and "we will do leaf art at home with park leaves." The children were simply happy to learn about plants and nature: "now I value nature more," "the leaf art was amazing," and "I want to play games with plants." These comments were analyzed for word frequency, and as seen in Table 4, "Leaf" and "Craft" obtained a total of 14 points. Participants next enjoyed learning about $H$. cordata, and changed their perspectives about it and M. bombycis: "I didn't like the smell of Dokudami, but now I am interested in it, so I am glad," "I liked doing leaf art with Dokudami and Kuwa leaves", and "doing many things with Dokudami and drinking the tea was good." The research suggests that the lower number for M. bombycis may be due to the lack of psychological polarity; is not as shocking to change the PO as $\mathrm{H}$. cordata. Moreover, the ingestion of M. bombycis was not done, therefore less PO may have been generated. Finally, one of the findings as a limitation was that there may be difficulties in social TK transmission due to differing names between common names and medicinal names for the same plant (II.5). One caretaker who wanted to buy the tea seemed perplexed at the different naming at the drug store.

Overall, the comments from the lessons indicated that leaf-craft and tea had affected PO from levels of strong feelings of interest, liking the plants, and further, to future plans for actions involving them.

\subsubsection{Increasing intensity of PO was observed with different EE methods (I.1-5 \& II.1-5)}

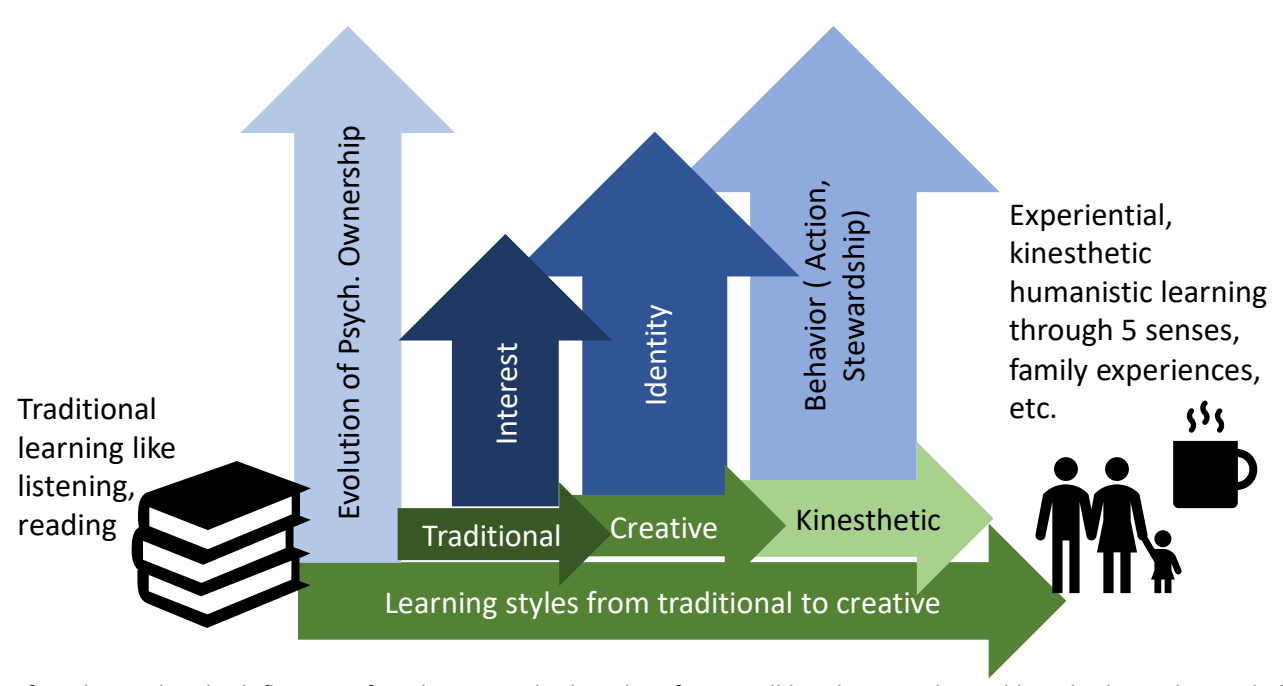

Figure 3 Diagram of study results: the influence of environmental education, from traditional to creative to kinesthetic on the evolution of psychological ownership of ethnobotanical plants

The results of the overall increase in PO of $H$. cordata through Process II.1-5 is shown in Figure 3. The research indicates that the combination of time-spent in the classroom, humanistic tactile and kinesthetic learning, creative process incorporating power of decision, activities involving caretakers, age, previous interests and deepened knowledge all affected the levels of PO of the ETBs in different ways for participants ranging from high interest to identity to plans for behavioral changes involving the target plants. In addition, Maslow's hierarchy of needs fits well, as the most basic need, physiological, was addressed by the cooling tea on the hot summer day, thus creating a fundamental understanding of affinity for the plant. The crafts addressed the central higher need for love and belonging 
when done with caretakers. Feelings of esteem could be gained from creative activities as well. Both of these needs were be nurtured by the EE teacher as participants were encouraged to interact positively with the plant and each other (Maslow, 1943).

The evolution of PO, from interest to identity to behavior, such as stating that they would buy the tea or play with $H$. cordata in the park, when juxtaposed with the EE actions associated with these in tandem, demonstrates that increasingly humanistic kinesthetic learning patterns result in greater PO of the focus ETB plant. This relationship is shown in the diagram in Figure 3.

\subsection{Limitations}

Practical limitations were numerous, and the study more complex, in the second summer. Some children could not legally drink the tea because permission had not been obtained. In addition, exact numbers for pleasure regarding the tea-drinking were not taken. However, there was a clear consensus among the university organizers and the researcher that the tea-drinking was participants' most animated and exclamatory part of the lesson.

As for issues with the questionnaire handout, two children in the morning were under the requested age limit and could not write. In the afternoon, caretakers were requested to ask small children's opinions, however two had to be asked repeatedly not to write their own opinions instead of asking children. In Process II, missing, illegible and incomplete questionnaires had to be discarded. Ideally, questionnaire data would be gathered in a fashion appropriate to all ages.

\subsection{Conclusion}

This research aimed to study how change in adults' and children's perceptions through environmental education (EE) might affect PO of ETBs. The specific objective of this paper was to find what exactly in EE might increase PO, to result in interest of ETB plants. The study revealed that the relationship between ETB and PO can be intensified from interest to identity to behavior through increasingly creative and kinesthetic humanistic EE. Although caretakers might influence children with their negative perceptions of ETBs, through guidance in the EE classroom this can be mitigated. Moreover, the combination of traditional lecture-style EE with the ETBs as unusual materials of traditional knowledge in a creative kinesthetic learning environment was effective in changing PO. By encouraging questions particular to age group and interests, aversion was reduced and interest piqued. PO was determined by interim and final commentary regarding near-future planned behavior, revealing continuous changes throughout the study, and culminating in a clear transition towards PO of ETBs. This research is significant to the fields of education and psychology as well as ethnobotany. In education, it provides further foundations for widening the area of Content and Language Integrated Learning (CLIL). In the field of psychology, it adds new possibilities for application and research of $\mathrm{PO}$, and deepens possibilities for advancement of that particular field relevant to sustainability and other environmental research. In ETB it shows new methods for teaching TK relevant in the modern world through EE. Applicable to planning, it can be used for sustainable community development workshops. The authors hope that professionals of many disciplines will recognize the potential in this interdisciplinary study and utilize it to better convey meaning and create PO of ETBs and TK in the modern world, not only in the classroom. Further, we recommend that humanistic creative and kinesthetic methods of EE involving food and medicine from ETBs be used to instil PO and provide cultural education. It is hoped that this type of EE will be used intergenerationally to promote communication as well as retention of TK in all ages of community. New directions for further research might include research on other ETB plants or with different stakeholder groups or substituting other creative teaching methods to experiment with how they affect the PO of ETBs.

\subsection{Acknowledgements}

We would like to thank Seitoku University for their invaluable aid in making this study possible. We are also humbly grateful to the children and their caretakers for consenting to participate in the study as classroom lessons. In addition, many thanks to Mr. Filippo Guzzon for his suggestions on an earlier version of this manuscript.

\subsection{References}

Antlová, A., Chudý, Š., Buchtová, T., \& Kučerová, L. (2015). The Importance of Values in the Constructivist Theory of Knowledge. Procedia - Social and Behavioral Sciences, 203, 210-216.

Caciuc, V.-T. (2014). Reflections on the Ways to Build up Responsibility towards Nature in Primary School. Procedia - Social and Behavioral Sciences, 149, 136-141.

Davies, D., Jindal-Snape, D., Collier, C., Digby, R., Hay, P., \& Howe, A. (2013). Creative learning environments in education-A systematic literature review. Thinking Skills and Creativity, 8, 80-91.

Dayaratne, R. (2016). Creating Places through Architecture: Can environment-behaviour research help? Asian Journal of Behavioural Studies, 1(2), 1-12.

Elena, D. (2015). Reconsidering the Didactic Practices from the Perspective of the Respect for the Educated Person's Individuality. Procedia - Social and Behavioral Sciences, 180, 293-297.

Guerra, M., \& Zuccoli, F. (2014). Unusual Materials in Pre and Primary Schools: Presence and Actions. Procedia - Social and Behavioral Sciences, 116, $1988-1992$. 
Higashimura, T. (2012). The Mutual Development between the Art Workshop and the Kindergarten Environment: Focusing on the Process of 'Discovery' by Teachers and Children. [in Japanese]

Kinoshita, I. (1992). A Study on Children's Contacts to Nature in Rural Areas Compared with Urban Areas: Part 1 Studies on aspects of the function's for environmental study through children's play in rural nature spaces. Journal of Architecture, Planning and Environmental Engineering (Transactions of AIJ), 431(0), 107-118. [in Japanese].

Maslow, A. H. (1943). A theory of human motivation. Psychological Review, 50(4), 370.

Md. Sharif, M. S., Mohd Zahari, M. S., Md Nor, N., \& Muhammad, R. (2018). Can Traditional Food Knowledge Be Transferred? Asian Journal of Behavioural Studies, 3(11), 15-25.

Meiboudi, H., Karimzadegan, H., \& Khalilnejad, S. M. R. (2011). Enhancing children's environmental awareness in kindergarten of Mashhad city using mural painting. Procedia - Social and Behavioral Sciences, 28, 1020-1028.

Momir, B., Petroman, I., Constantin, E. C., Mirea, A., \& Marin, D. (2015). The Importance of Cross-Cultural Knowledge. Procedia - Social and Behavioral Sciences, 197, 722-729.

Murakami, K. (2011). Q\&A for preparing Houttuynia juice for a Houttuynia alcoholic beverage. Modern Agriculture (Assn. of Agricultural Mountain Fishing Villages), 90(6), 328-333. [In Japanese]

Mustafa, M., Rustam, N., \& Siran, R. (2017). Fragrance Impact on Driving Performance. Asian Journal of Quality of Life, 2(5), 21-30.

Palinkas, L. A., Horwitz, S. M., Green, C. A., Wisdom, J. P., Duan, N., \& Hoagwood, K. (2015). Purposeful Sampling for Qualitative Data Collection and Analysis in Mixed Method Implementation Research. Adm Policy Ment Health, 42(5), 533-544.

Pecheanu, I. S. E., \& Tudorie, C. (2015). Initiatives Towards an Education for Creativity. Procedia - Social and Behavioral Sciences, 180, $1520-1526$.

Penabaz-Wiley, S. (2017). Eating Houttuynia. HortResearch, 71, 8-9

Petrenko, M. (2017). Typological Characteristics of the Intercultural Humanitarian Educational Technologies. Procedia - Social and Behavioral Sciences, 237, 520-526.

Pierce, J. L., Kostova, T., \& Dirks, K. T. (2003). The state of psychological ownership: Integrating and extending a century of research. Review of General Psychology, $7(1), 84-107$.

Saliceti, F. (2015). Educate for Creativity: New Educational Strategies. Procedia - Social and Behavioral Sciences, 197, $1174-1178$.

Sharif, M. S. M., Nor, N. M., Zahari, M. S. M., \& Muhammad, R. (2015). What Makes the Malay Young Generation had Limited Skills and Knowledge in the Malay Traditional Food Preparation? Procedia - Social and Behavioral Sciences, 202, 152-158.

Sharif, M. S. M., Zahari, M. S. M., Nor, N. M., \& Muhammad, R. (2016). The Importance of Knowledge Transmission and its Relation towards the Malay Traditional Food Practice Continuity. Procedia - Social and Behavioral Sciences, 222, 567-577.

Shogakukan. (1985). Chüyaku Daijiten. Tokyo: Shogakukan. [In Japanese]

Soejarto, D. D., Fong, H. H., Tan, G. T., Zhang, H. J., Ma, C. Y., Franzblau, S. G., . . Dietzman, G. R. (2005). Ethnobotany/ethnopharmacology and mass bioprospecting: issues on intellectual property and benefit-sharing. Journal of Ethnopharmacology, 100(1-2), 15-22.

Soykan, A., \& Atasoy, E. (2012). Historical Development of Non-Formal Environmental Education in Turkey. Procedia - Social and Behavioral Sciences, $46,736-743$.

Valderrama-Hernández, R., Alcántara, L., \& Limón, D. (2017). The Complexity of Environmental Education: Teaching Ideas and Strategies from Teachers. Procedia Social and Behavioral Sciences, 237, 968-974.

Wan Yunus, F., \& Mat Ali, Z. (2018). Attitude towards Learning Chemistry among Secondary School Students in Malaysia. Asian Journal of Behavioural Studies, 3(9), $63-70$.

Wiegerová, A., \& Navrátilová, H. (2017). Let's Not Be Scared of Comics (Researching Possibilities of Using Conceptual Comics in Teaching Nature Study in Kindergarden). Procedia - Social and Behavioral Sciences, 237, 1576-1581.

Yang, L., \& Jiang, J.-G. (2009). Bioactive components and functional properties of Hottuynia cordata and its applications. Pharmaceutical Biology, 47(12), $1154-1161$. Yuri, M. (2010). Dokudami, The Japanese Herb. Visiting Nursing and Long-term Care, 15(8), 668-669. [In Japanese]

Zivitere, M., Riashchenko, V., \& Markina, I. (2015). Teacher - Pedagogical Creativity and Developer Promoter. Procedia - Social and Behavioral Sciences, 174, 40684073. 